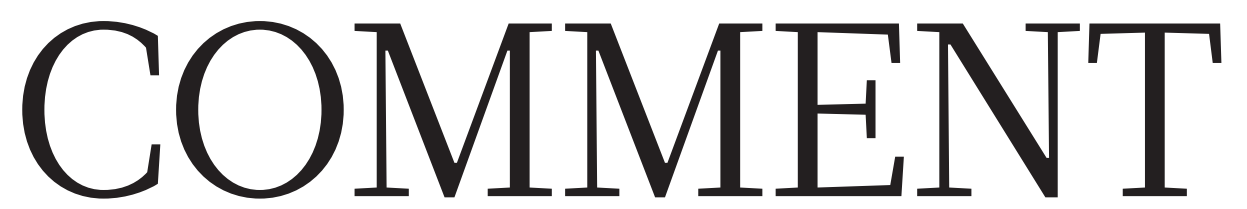

PHYSICS The struggle for the soul of solid-state science $\mathbf{p . 3 0 6}$
HISTORY Polish team paved

the way for Turing to crack Enigma p.307
BIODIVERSITY Stakeholders in international panel rise up and respond p.309
NATURAL CAPITAL Guidelines, respect and time can reconcile diverse views $\mathbf{p . 3 0 9}$

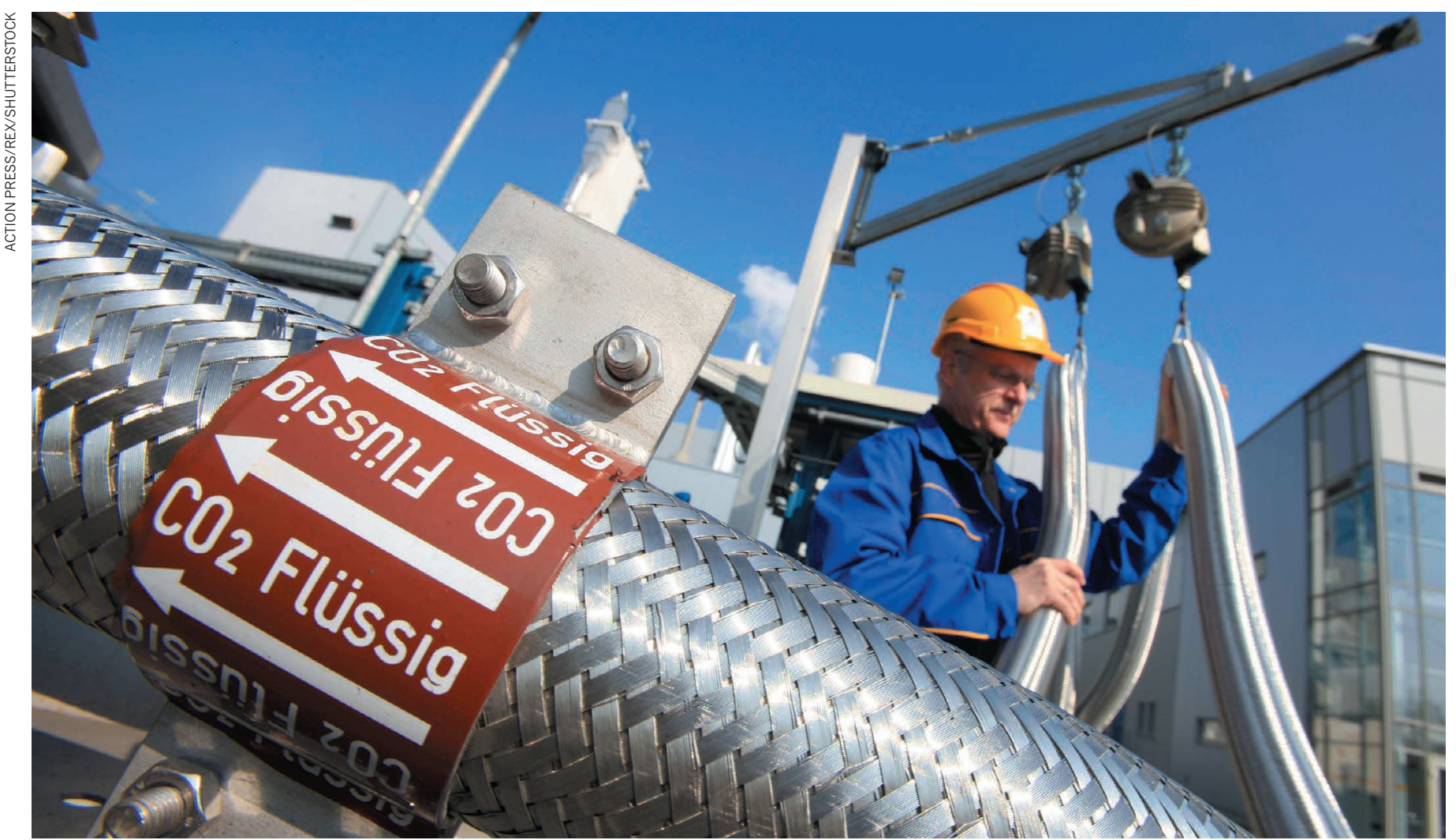

A pilot project in Spremberg, Germany, aims to capture carbon dioxide released from power stations.

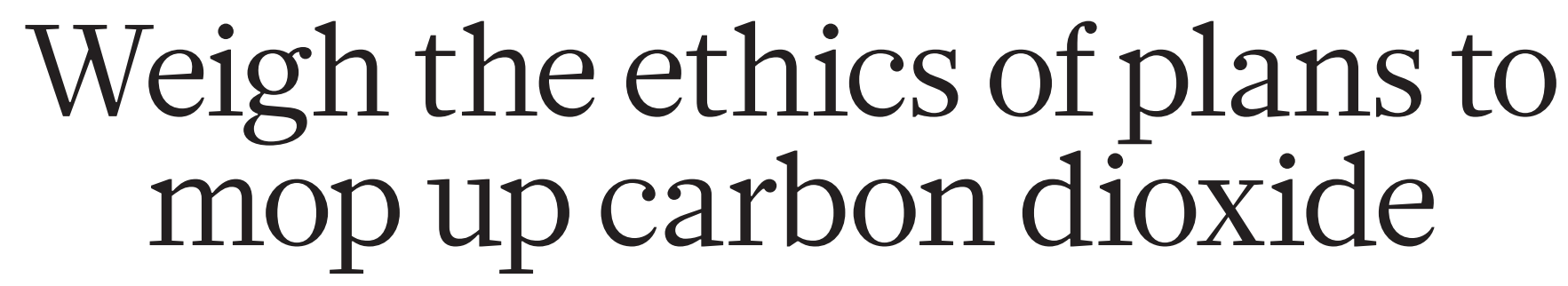

Pinning climate hopes on negative emissions technologies is dangerous and demands reflection on the social aspects, warn Dominic Lenzi and colleagues.

$\mathrm{I}$

n October, the Intergovernmental Panel on Climate Change (IPCC) will release a special report on keeping global temperature rise within $1.5^{\circ} \mathrm{C}$ of pre-industrial levels. Governments requested the report at the 2015 Paris climate conference. Policymakers want to know what further steps would be needed to stay well within the $2{ }^{\circ} \mathrm{C}$ threshold, above which the risks of climate change become more dangerous.

The IPCC report will confirm an open secret: in the light of growing emissions, targets for mitigating climate change increasingly depend on 'negative emissions technologies' that suck carbon dioxide out of the atmosphere. Staying within $2{ }^{\circ} \mathrm{C}$ could mean extracting billions of tonnes of $\mathrm{CO}_{2}$ this century.

Atmospheric carbon - captured after burning biofuels, for instance - could be locked in the ground or sea for thousands of years. Forests and soils could be managed to store more carbon. Or more-speculative means that are still in the realm of basic research could be used ${ }^{1}$. Examples include fertilizing the oceans with iron to enhance phytoplankton growth, increasing the weathering of minerals or developing devices that remove $\mathrm{CO}_{2}$ directly from the air.

The vast scale at which such technologies would need to be implemented raises ethical concerns. For example, growing more biomass to burn as fuel would take land away from food production and use water for irrigation ${ }^{2}$. Famines, civil unrest and damage to biodiversity could follow ${ }^{3}$. 
- Seeding the oceans with iron could undermine marine ecosystems. Covering an area twice the size of the United States with crushed silicate stones to enhance weathering would affect communities, agriculture and ecosystems.

Yet there has been no systematic evaluation of the ethics of carbon removal methods by the climate assessment community or professional philosophers. The IPCC's latest review (its fifth assessment report) included a chapter on ethics ${ }^{4}$, setting out concepts of responsibility, justice and welfare. But it did not dwell much on negative emissions technologies, nor did other chapters consider ethics. Carbon removal methods must be ethically evaluated in the context of climate policy pathways.

The key question is, which pathways are most compatible with human rights, sustainable development and environmental protection? The stakes are high. Negative emissions technologies could be a valuable way to avoid dangerous climate change. But they might become an unjust gamble that uses future generations as collateral ${ }^{5}$.

\section{MISSING ETHICS}

Why has this aspect of negative emissions been overlooked? Ethicists neglect the science; modellers neglect the ethics. Geoengineering debates have been dominated by solar-radiation management - altering the reflectivity of the whole atmosphere seems more dystopian than growing forests or storing carbon. Early studies suggested that negative emissions technologies were largely benign ${ }^{6}$. Growing dependence on negative emissions increases the risks, but most ethicists have not noted this shift.

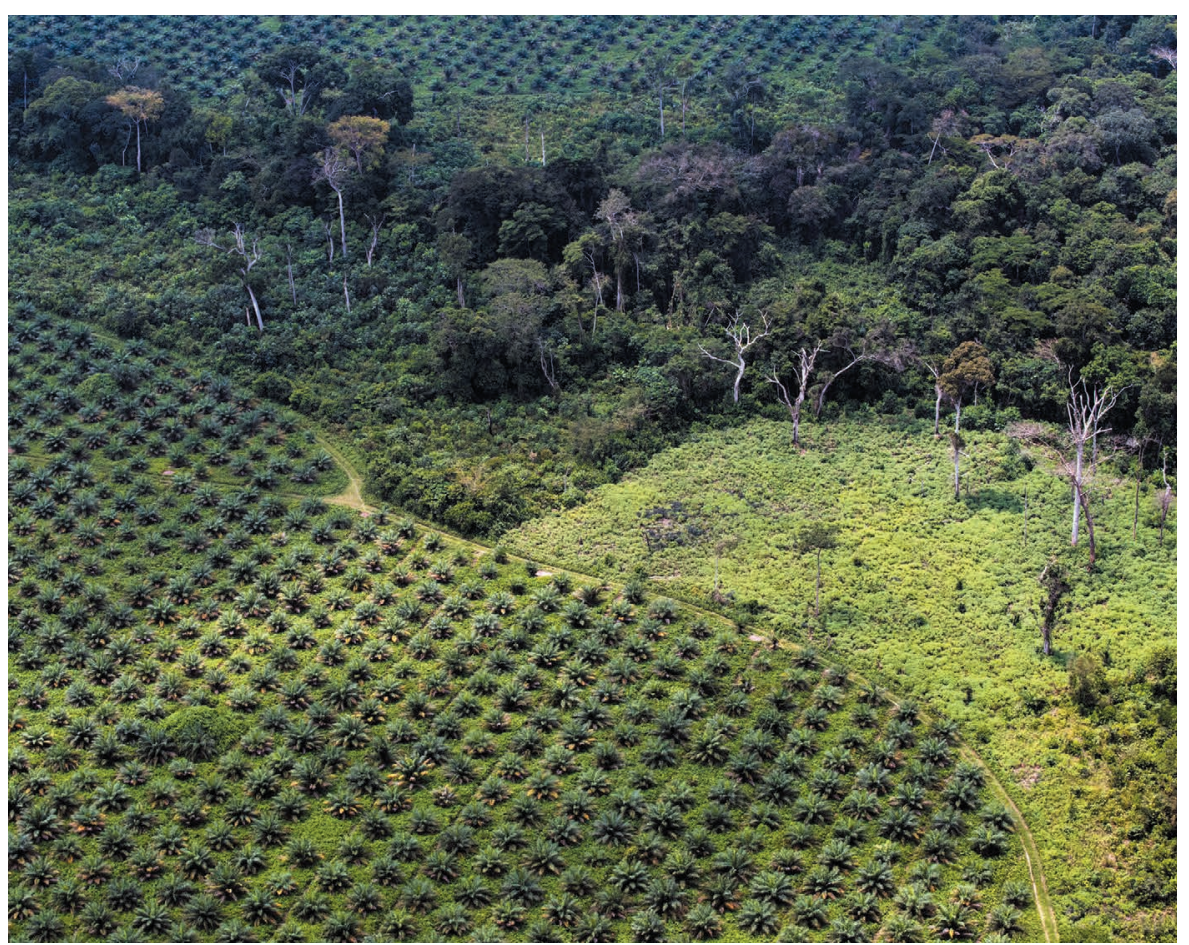

A palm-oil plantation in the Democratic Republic of the Congo encroaches on nearby rainforest areas. change revolve around abstract principles: the 'common but differentiated responsibilities of states' to fund mitigation and adaptation, whether the polluter pays and who has the ability to pay. The debates do not consider particular policy pathways, telling us little about what a just future would look like or how to achieve it. Without interrogating mitigation pathways, ethics will be of little use for policy assessment.

Ethicists need a better understanding of over which negative emissions technologies would be unleashed are difficult to grasp. Even the climate stabilization target isn't settled. It seems obvious that lower temperatures are ethically preferable. But getting negative emissions wrong also raises risks. Keeping within $1.5^{\circ} \mathrm{C}$ of warming could cause side effects that are as bad as those in a world that is $2^{\circ} \mathrm{C}$ warmer - such as through environmental damage caused by ramping up mineral mining, or cutting down the rest of the Amazon rainforest for biofuels.

\section{VALUES IN DISGUISE}

Meanwhile, modellers inevitably make value-laden assumptions in charting different policy pathways, including the range of options being considered, such as rapid technological development or nuclear energy. Assumptions also include the political, economic and demographic stories behind
Philosophical discussions of climate climate-mitigation research. The vast scales them, such as steady population growth or declining international cooperation. For example, the IPCC included negative emissions technologies in its 'default' technology mix, even though some of these solutions might never be viably scaled up ${ }^{7}$.

A lack of transparency and ethical discussion has three consequences. First, policymakers have false expectations. This is the 'moral hazard' worry: if politicians and advisers think it is acceptable to emit carbon now and claw it back later, they might take more risks and obstruct mitigation in the real world $^{8}$. For example, in IPCC scenarios with $\mathrm{CO}_{2}$ retrieval, emissions from fossil fuels and industry can remain as high as 32 gigatonnes of $\mathrm{CO}_{2}$ in 2030 (see 'Three-fold folly', top left panel). Without $\mathrm{CO}_{2}$ removal, emissions would have to be reduced to 23 gigatonnes of $\mathrm{CO}_{2}$ by 2030 - a difference almost equivalent to China's emissions each year since 2008 .

Second, designing climate policy around technologies that might never scale up is risky ${ }^{7}$. A typical $2{ }^{\circ} \mathrm{C}$ climate scenario requires the funding, construction and operation of as many as 16,000 plants that combine biomass burning with carbon capture and storage by 2050 . Today there are three demonstration projects (see 'Three-fold folly', top right panel). If the bet fails, future generations will face a carbon overdraft and warming that is greater than $2^{\circ} \mathrm{C}$ (ref. 3 ).

Third, implementing negative emissions at the scales envisaged is ambitious, to say the least ${ }^{5}$. According to many models, this would mean managing an artificial carbon sink that is larger than the entire land sink today (see 'Three-fold folly', lower panel). Assessments also must not ignore a host of potential feedback mechanisms and tipping points that are poorly understood, such as whether temperature overshoot might trigger permafrost melting?

\section{DRAW ON DIVERSE VIEWS}

A cultural change is required across the climate-change community. As for humanparticipants research in bioscience, ethicists need to be involved from the outset in developing, modelling and evaluating scenarios for reducing emissions. The IPCC should integrate the perspectives of these experts across all chapters of its reports. There are no plans to do this within the sixth IPCC review currently in preparation.

To broaden the range of considerations included, we would like to see ethicists, modellers and social scientists, governments and civil-society groups collaborate on climate-mitigation assessments. Drawing on divergent viewpoints and criteria, they should map the various implications of alternative policy pathways ${ }^{10}$. Organizations such as the Integrated Assessment Modeling Consortium should openly discuss ethical assumptions built into models. This might help to avoid misleading or opaque choices 
Technologies that capture carbon dioxide on a planetary scale might help to avert dangerous levels of climate warming, but they are risky.

\section{COULD DELAY CUTS}

Policymakers and industry could delay the reduction of emissions in the belief that these can be clawed back later with negative emissions.

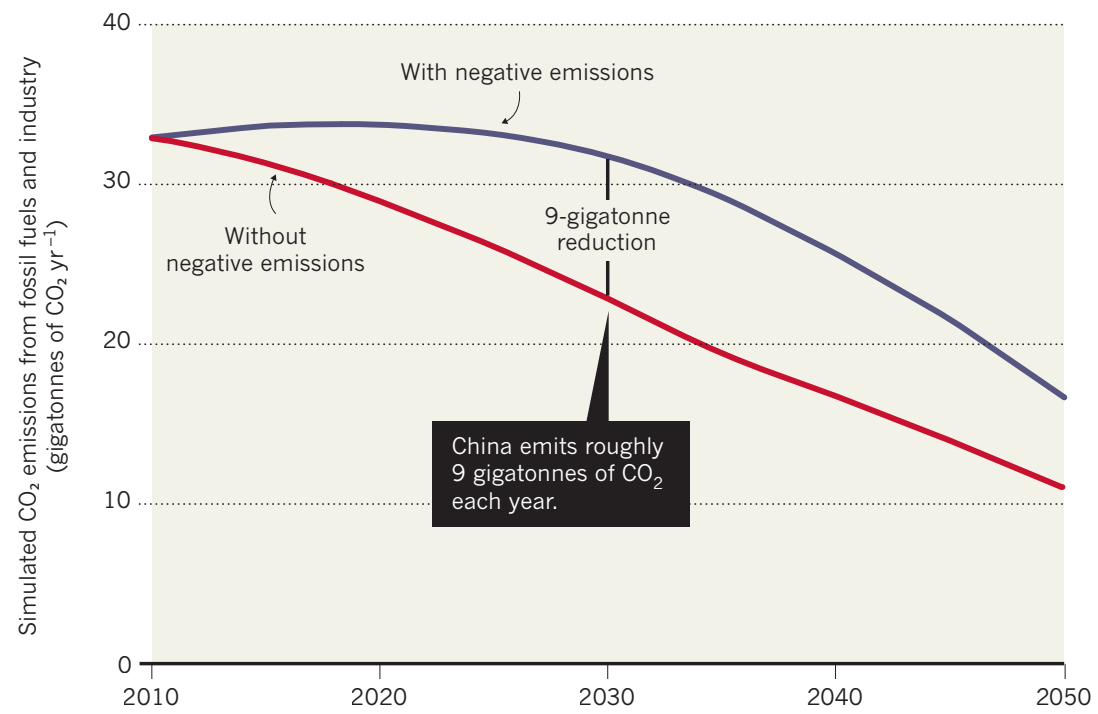

\section{REQUIRES STEEP SCALE-UP}

Designing climate policy around technologies that might never sufficiently scale up is a gamble.

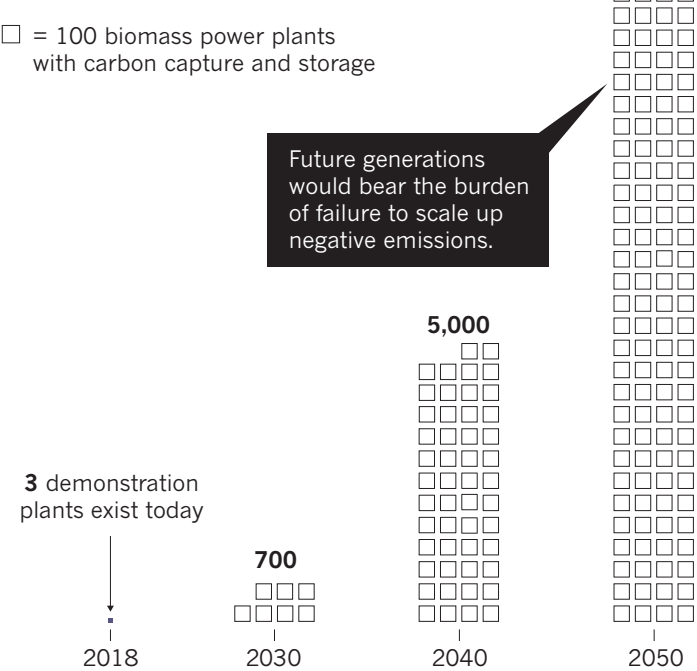

\section{DEMANDS UNPRECEDENTED SINK}

The scale of negative emissions required in many scenarios would mean controlling a massive carbon sink (purple bar) - larger than the entire current natural land sink.

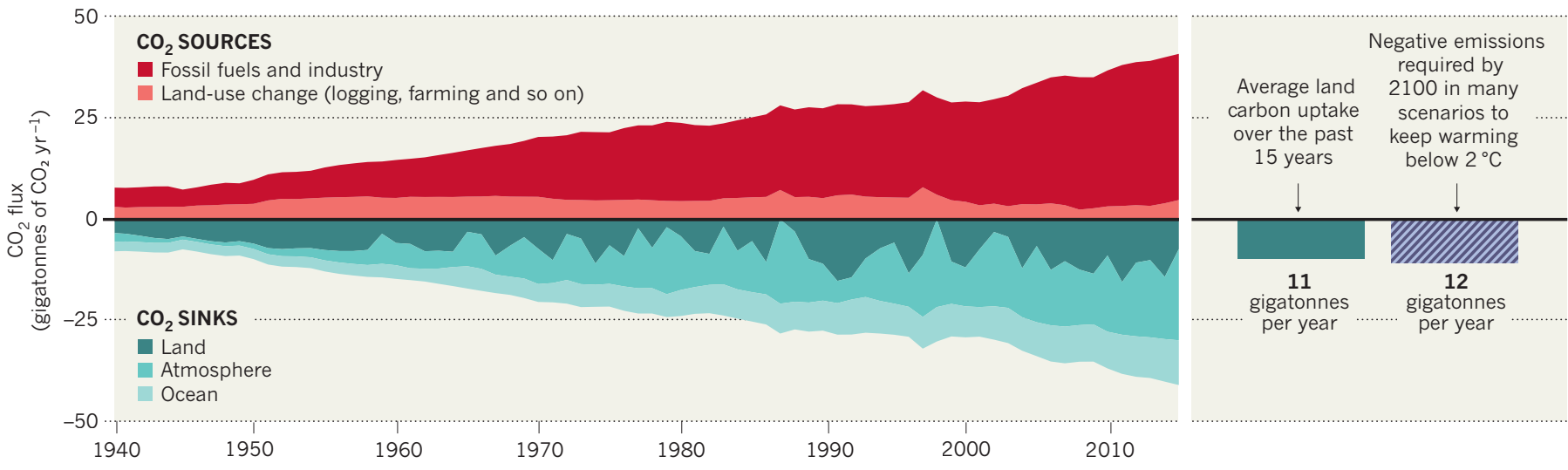

being made at the design stage. For example, lifestyle changes such as meat-free diets or avoidance of aeroplane travel have been absent until recently from scenarios, leading to an imbalanced representation of options ${ }^{11}$. Jointly assessing the desirability of alternative futures against ethical principles and the policy goals underlying sustainable development would facilitate critical reflection on negative emissions. Funding bodies such as the European Commission, Future Earth, the US National Science Foundation and other supporters of interdisciplinary research must integrate ethical and social analyses with climate scenario modelling and policy evaluation.

How else can we debate the sort of future we want? -

Dominic Lenzi, William F. Lamb and Jérôme Hilaire are researchers at the
Mercator Research Institute on Global Commons and Climate Change, Berlin, Germany. Martin Kowarsch is head of scientific assessments, ethics and public policy and Jan C. Minx is head of applied sustainability science at the Mercator Research Institute. J. H. is also at the Potsdam Institute for Climate Impact Research, Germany; and J. C. M. is also at the School of Earth and Environment, University of Leeds, $U K$. e-mail:lenzi@mcc-berlin.net

1. Nemet, G. F. et al. Environ. Res. Lett. 13, 063003 (2018).

2. Creutzig, F. et al. Glob. Change Biol. Bioenergy 7, 916-944 (2015)

3. Shue, H. J. Hum. Rights Environ. 8, 203-216 (2017).

4. Kolstad, C. et al. in Climate Change 2014: Mitigation of Climate Change. Contribution of Working Group III to the Fifth Assessment Report of the Intergovernmental Panel on Climate
Change (eds Edenhofer, O. et al.) Ch. 3, 207-282 (Cambridge Univ. Press, 2014).

5. Lenzi, D. Glob. Sustain. 1, e7 (2018).

6. Shepherd, J. et al. Geoengineering the Climate: Science, Governance and Uncertainty (Royal Soc. 2009).

7. Fuss, S. et al. Nature Clim. Change 4, 850-853 (2014)

8. Minx, J. C. et al. Environ. Res. Lett. 13, 063001 (2018).

9. Fuss, S. et al. Environ. Res. Lett. 13, 063002 (2018)

10. Kowarsch, M. et al. Nature Clim. Change 7, 379-382 (2017).

11.Creutzig, F. et al. Nature Clim. Change 8, 260-263 (2018)

\section{CORRECTION}

The timeline in the Comment 'Publish peer reviews' (Nature 560, 545-547; 2018) erroneously stated that peer review began to be published at The EMBO Journal in 2010. It was, in fact, in 2009. 